\title{
Gold Nanoparticles Enhance Efficiency of In Vitro Gene Transcription-Translation System
}

\author{
Daxiang Cui ${ }^{1,2}$, Hong Zhang ${ }^{1}$, Kan Wang ${ }^{2}$, Feng Gao ${ }^{2}$, Xueqing Zhang ${ }^{2}$, Toru Asahi ${ }^{1}$, Rong He $^{2}$, Tetsuya Osaka ${ }^{1}$
}

${ }^{1}$ Consolidated Research Institute for Advanced Science and Medical Care, Waseda University, 513Wasedatsurumaki-cho, Shinjuku-ku, Tokyo 1620041, Japan

${ }^{2}$ Department of Bio-Nano-Science and Engineering, National Key Laboratory of Nano/Micro Fabrication Technology, Key Laboratory for Thin Film and Microfabrication of Ministry of Education, Institute of Micro-Nano Science and Technology, Shanghai JiaoTong University, 800 Dongchuan Road, Shanghai 200240, People's Republic of China

* Corresponding author: dxcui@sjtu.edu.cn

\begin{abstract}
Herein we report that the in vitro gene transcription-translation efficiency can be dramatically enhanced by gold nanoparticles of $5 \mathrm{~nm}$ in diameter. The addition of less than or equal to $1.2 \mathrm{nM}$ of gold nanoparticles of $5 \mathrm{~nm}$ in diameter into rapid-translation-system (RTS) reagents increased the transcription-translation efficiency up to $30 \%$ and shortened the reaction time to $4 \mathrm{~h}$, with the same or higher translation yields. Gold nanoparticles did not decrease the yields' bioactivity. The results show that gold nanoparticles of $5 \mathrm{~nm}$ may act as a bio-catalyst in the RTS reaction. This innovation has great potential in applications such as large-scale protein fabrication, gene transcription-translation regulation, and studies of structure and function of toxic protein.
\end{abstract}

Keywords: Gold Nanoparticle, Rapid Translation System, Efficiency

Citation: Daxiang Cui. et al. Gold Nanoparticles Enhance Efficiency of In Vitro Gene Transcription-Translation System. Nano Biomed. Eng. 2011, 3(2), 120-125.DOI: 10.5101/nbe.v3i2.p120-125.

\section{Introduction}

The in vitro replications of some important in vivo biological processes have significant potential for fundamental studies and applications development in biology and medicine. For example, the polymerase chain reaction (PCR) [1] and the rapid translation system (RTS) [2] were developed to realize specific targets such as obtaining a lot of gene fragments or peptides within several hours. However, it is very difficult for in vitro replication courses to achieve the same efficiency and specificity as in vivo courses, because in vivo biochemistry reactions involve the synergistic action of a lot of biomolecules, like the operation of a molecular machine [3-6]. Moreover, because of current technical difficulties, it is impossible for in vitro mimicking biochemical reaction courses to be reproduced as in vivo biochemical reactions. For example, RTS uses a coupled transcription-translation reaction for in vitro protein synthesis [7-10], in which the transcription and translation occur simultaneously, while the T7-RNA-polymerase transcribes the template gene and the ribosomes from the E. coli lysate start to translate the 5'-end of the nascent mRNA. So far, this cell-free synthesis system provides some advantages and has great potential both as an analytical tool and a method for the efficient production of recombinant proteins. Although RTS has been applied successfully to in-vitro protein synthesis, key factors such as efficiency and production bioactivity still need improvement. Currently, there are some methods to improve RTS efficiency and production bioactivity: for example, decreasing the reaction temperature to $20{ }^{\circ} \mathrm{C}$. adding a second mixture of amino acids into the reaction, extending the reaction time, and using mutation T7 RNA polymerase to replace the real T7 RNA polymerase [11-15]. However, these methods still cannot improve the efficiency and yield bioactivity of RTS to the levels that are required in modern biomedicine.

Nanoparticle-based nanotechnology provides a new functional platform for medical chemistry and biomedical engineering, because nanoparticles have unique physical, chemical, optical, and mechanical properties [16-19]. Specifically, the use of nanoparticles as bio-catalysts has been very successful [20]. For example, silver nanoparticles can be used to catalyze 
the chemiluminescence of luminal [20]. Also, nanoparticles such as carbon nanotubes [21] and gold nanoparticles [22] have been used as supports for enzymes. Nanoparticles also enhance the stability of adsorbed proteins relative to micro- or macro-scale supports, thereby helping to preserve or enhance enzyme bioactivity in nanocomposites [19, 22-25]. Furthermore, recent studies show that nanoparticles can function as replacement for some proteins or enzymes. For example, nanoparticles such as single-walled carbon nanotubes [25] and gold nanoparticles(GNPs) [26-28] can improve the efficiency or specificity of PCR, which highly suggest that nanoparticles are capable of acting as a biocatalyst to enhance the bio-activity of Taq DNA polymerase and as a single-strand binding protein (SSB) [29] to improve strict base-pairing in the course of PCR. Since numerous enzyme-catalyzed biochemical reactions are involved in the course of RTS $[30,31]$, it is very possible that gold nanoparticles could improve both the bioactivities of enzymes such as aminoacyl-tRNA synthetases, RNA polymerase, ribozymes, etc, and the efficiency of coupling mRNA to ribosome and also amino acids to tRNA, thereby speeding up the course of transcription and translation. In other respects, gold nanoparticles could possibly act as a single-strand binding protein (SSB) in RTS, similar to their role in the course of PCR $[25,28]$, ensuring correct molecule-pairing such as that between amino acids and tRNA and between mRNA and ribosomes. Therefore, it is likely that gold nanoparticles may markedly enhance the efficiency of RTS. However, the coupled in-vitro transcription-translation system is a complicated process, in which transcription and translation are processed simultaneously and all the necessary components for transcription and translation (as well as the synthesized products) are mixed together [27], all of which involves the synergistic action of lot of biomolecules. So far, there have been no reports on the possible effects of the addition of gold nanoparticles to this complicated system.

It is, therefore, the first report on these effects in this letter by our group. We found that the gold nanoparticles with a $5 \mathrm{~nm}$-diameter can markedly improve both the efficiency and the bioactivity of yield of the in-vitro transcription-translation system. This new finding has great potential in applications such as large-scale protein fabrication, gene transcription-translation regulation, and studies on structure and function of toxic protein.

\section{Experiments}

\subsection{PCR primers and PCR cycles}

The fragment A1, corresponding to amino acids 1006 to 1118 of BRCAA1 protein [32], was selected. This region includes a new breast cancer antigen epitope SSKKQKRSHK. Two primers with introduction of a COOH-terminal His-tag were designed and chemically synthesized by Gibico Inc.,Germany. Their sequences were as follows: primer1: 5'-CTT TAA GAA GGA
GAT ATA CCA TGA GAG TGA AAG ATG CTC AG3'; primer2: 5'-TGA TGA TGA GAA CCC CCC CCA CTC CAT TTG TAA ACT TTG G-3'. The PCR product was $339 \mathrm{bp}$ in length. PCR reaction 1 was used to obtain specific fragment A1: $10 \times$ PCR buffer $3 \mathrm{uL}, 2.5 \mathrm{~mm}$ deoxynucleotide triphosphate $3 \mathrm{uL}$, primer 1 and primer 2 each $1 \mathrm{uL}$, brcaal vector template $2 \mathrm{uL}, 25 \mathrm{~mm} \mathrm{MgCl}_{2} 3$ $\mathrm{uL}$, and Taq enzyme $1 \mathrm{uL}$ Sterilized water was added until the total volume was up to $30 \mathrm{uL}$. PCR condition: predenature at $94{ }^{\circ} \mathrm{C}$ for 4 minutes, then $94{ }^{\circ} \mathrm{C}$ for 1 minute, $55^{\circ} \mathrm{C}$ for 1 minute, $72{ }^{\circ} \mathrm{C}$ for 1 minute, 30 cycles, finally extend at $72{ }^{\circ} \mathrm{C}$ for 7 minutes. The PCR product was purified with a PCR purification kit.

\subsection{RTS reaction with or without gold nanoparticles}

PCR reaction 2 and a rapid-translation system (RTS) E. coli Linear Template Generation Set and His-tag kit (Roche Diagnostics Inc., Germany) were used to obtain specific fragment A2 of $720 \mathrm{bp}$ in length with regulatory elements and His-tag. Fragment A2 was purified with a PCR purification kit. An RTS 100 E. coli kit (Roche Diagnostics Inc., Germany) was used to translate the purified fragment A2 into corresponding peptides in the ProteoMaster (Roche Diagnostic Inc., Germany), under the following reaction condition: $50 \mathrm{uL}$ total volume, $30^{\circ} \mathrm{C}$ for $6 \mathrm{~h}$. Different amounts of gold nanoparticles with a diameter of $5 \mathrm{~nm}$ (Sigma Inc, USA, $75.1 \mathrm{nmol} \mathrm{L}^{-1}$ ) were added to the RTS reagent, the total volume of each tuber still was kept at $50 \mathrm{uL}$, and the reaction condition did not change.

\subsection{Yield analysis of RTS}

The protein products were analyzed by $10 \%$ SDSpolyacrylamide gel and thenstained by Coomassie brilliant blue and quantified by ultraviolet spectrophotometer. The peptide bio-activity was confirmed by Western blotting and by using a rabbit anti-human new antigen epitope IG $\mathrm{G}$ antibody (Abcam Company, UK), as discussed in references [32]. Enzymatic assays of aminoacyltRNA synthetase with or without GNPs were performed according to manual(aminoacyl-tRNA synthetase, A364610KU from ESwerichia coli, crude,Sigma).

\subsection{Statistical Analysis}

Each experiment was repeated three times in duplicate. The results were presented as mean \pm SD. Statistical differences were evaluated evaluated using the t-test and considered significance at $\mathrm{P}<0.05$.

\section{Results and Discussion}

\subsection{Characterization of gold nanoparticles and gold nanopartilces-yields composites}

The gold nanoparticles were characterized by highresolution transmission electron microscopy (HR-TEM) and ultraviolet spectrophotometer (UV). As shown in Fig. 1 , the gold nanoparticles are $5 \mathrm{~nm}$ in diameter and have a UV absorption peak at $522 \mathrm{~nm}$. The gold nanoparticles wrapped by the yield made by the rapid translation 

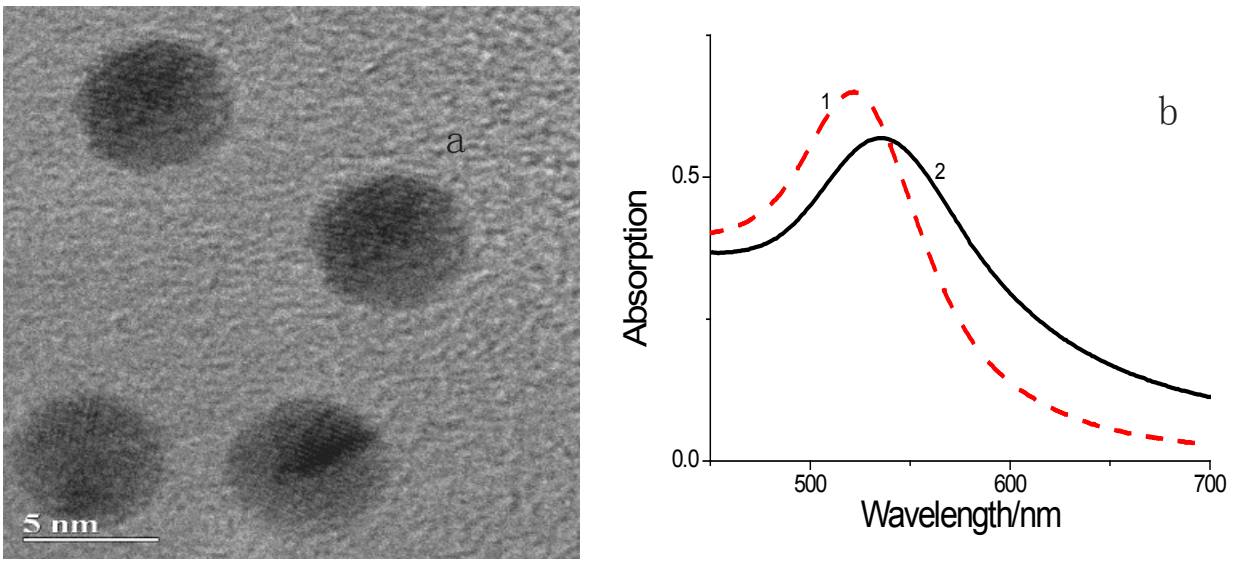

Fig. 1 Characterization of gold nanoparticles of $5 \mathrm{~nm}$ in diameter by HR-TEM and UV-spectroscopy. a. HR-TEM image of gold nanoparticles; b. UV-spectra of gold nanoparticles before RTS reaction (1) and after RTS reaction (2).

system (RTS) have a UV absorption peak at $536 \mathrm{~nm}$; this peak represents a $14 \mathrm{~nm}$ right-shift, which strongly suggests that there is a strong interaction between gold nanoparticles and synthesized yield.

\subsection{Effects of gold nanoparticles on efficiency of RTS}

The first round gene fragment was obtained by common PCR using brcaal vector as the template. The fragment A1 then was used as the template for the second roundPCR, which produced the fragment A2 with the necessary translational elements. Finally, the purified fragment A2 was used as the template for RTS. As shown in Fig. 2A, the fragment A1 was $339 \mathrm{bp}$ in length, and the fragment A2 was 720 bp in length.

Next, $0.24 \mathrm{~nm}, 0.48 \mathrm{~nm}, 0.72 \mathrm{~nm}, 0.96 \mathrm{~nm}, 1.2 \mathrm{~nm}$, $2.4 \mathrm{~nm}, 4.8 \mathrm{~nm}, 7.2 \mathrm{~nm}, 9.6 \mathrm{~nm}$, and $12 \mathrm{~nm}$ of $5 \mathrm{~nm}-$ diameter gold nanoparticles were added into different reaction tubes with the RTS reagents, and then the standard procedure of RTS was used to transcribe and translate the fragment A2 into short peptides. As shown in Fig. 2B, in the concentration range of less than or equal to $1.2 \mathrm{~nm}$, as the amount of gold nanoparticles in the RTS reagent gradually increased, the yield also gradually increased. The efficiency of synthesized yields was enhanced by $30 \%$ compared to the manual method, which shows that gold nanoparticles can improve the efficiency of in-vitro transcription-translation system. However, as shown in Fig. $2 \mathrm{C}$ in the concentration range of $1 \mathrm{uL}$ to $10 \mathrm{uL}$, as the amount of gold nanoparticles in the RTS reagent gradually increased, the yield peptides gradually decreased, showing that superfluous gold nanoparticles can inhibit the synthesis of peptide.

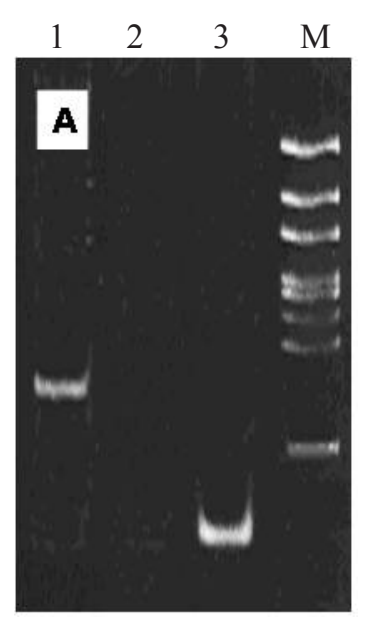

$\begin{array}{llllll}M & 1 & 2 & 3 & 4 & 5\end{array}$

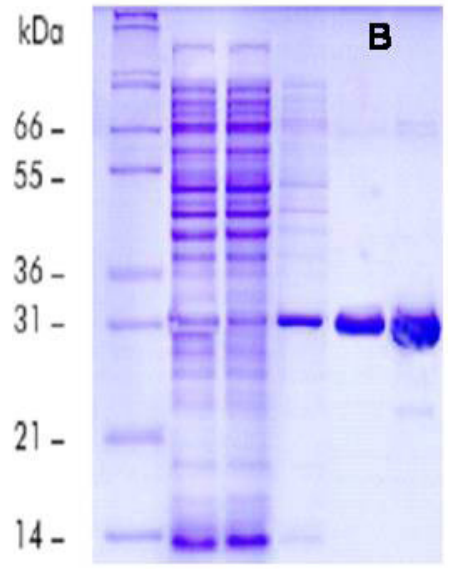

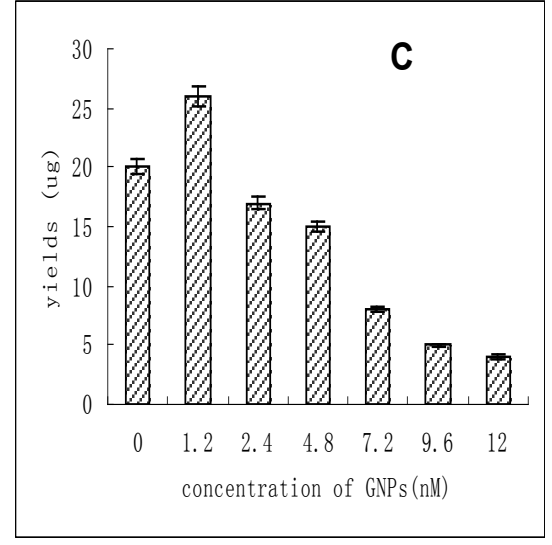

Fig. 2 Electrophoresis analysis of PCR products and RTS yields

A: Image of PCR products by $1 \%$ agarose gel electrophoresis. M is $\lambda$ DNA Hind III Marker; No.1 lane is fragment A2; No. 2 lane: negative control; No.3 lane: fragment A1.

B: Image of RTS yield by $15 \%$ SDS-PAGE electrophoresis. M is protein marker; No.1 lane is RTS yield without GNPs; No.2 lane is yield with $0.24 \mathrm{nM}$ GNPs; No.3 lane is yield with $0.48 \mathrm{nM}$ GNPs; No.4 lane is yield with $0.96 \mathrm{nM}$ GNPs; No.5 lane is yield with $1.2 \mathrm{nM}$ GNPs.

C: RTS yields respectively with $0 \mathrm{~nm}, 1.2 \mathrm{~nm}, 2.4 \mathrm{~nm}, 4.8 \mathrm{~nm}, 7.2 \mathrm{~nm}, 9.6 \mathrm{~nm}$ and $12 \mathrm{~nm}$ GNPs in the RTS reactions. 
To further confirm that gold nanoparticles can affect the efficiency of RTS, we prepared 6 tubes of RTS reagents, added $1 \mathrm{uLlof}$ gold nanoparticles to each tube, and then put the tubes into a Roche ProteinMaster instrument (Roche Diagnostics Inc.,Germany) for peptide synthesis under different times such as $1 \mathrm{~h}, 2 \mathrm{~h}, 3 \mathrm{~h}, 4 \mathrm{~h}, 5 \mathrm{~h}$, and 6 h. As shown in Fig. 3A, from $1 \mathrm{~h}$ to $4 \mathrm{~h}$ the peptide yields gradually increased, at $4 \mathrm{~h}$ the maximum yield of peptides was obtained, and at $5 \mathrm{~h}$ and $6 \mathrm{~h}$ the peptide yields leveled off. It should be noted that the control group needed 6 hours to reach maximum yield. The results show that gold nanoparticles with a diameter of $5 \mathrm{~nm}$ can shorten the time of peptide synthesis to $4 \mathrm{~h}$.

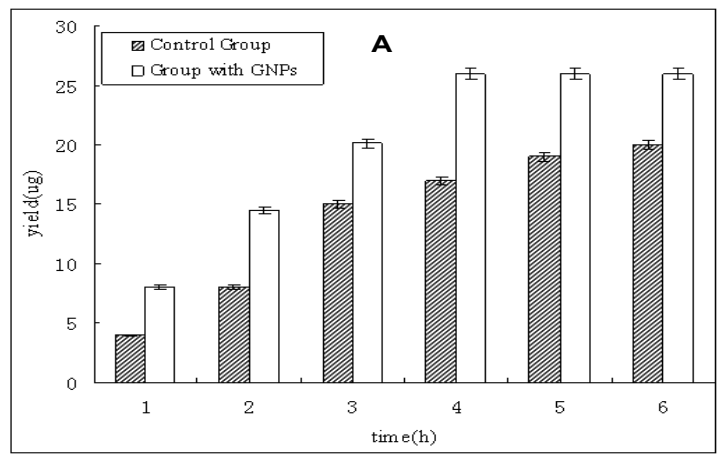

B
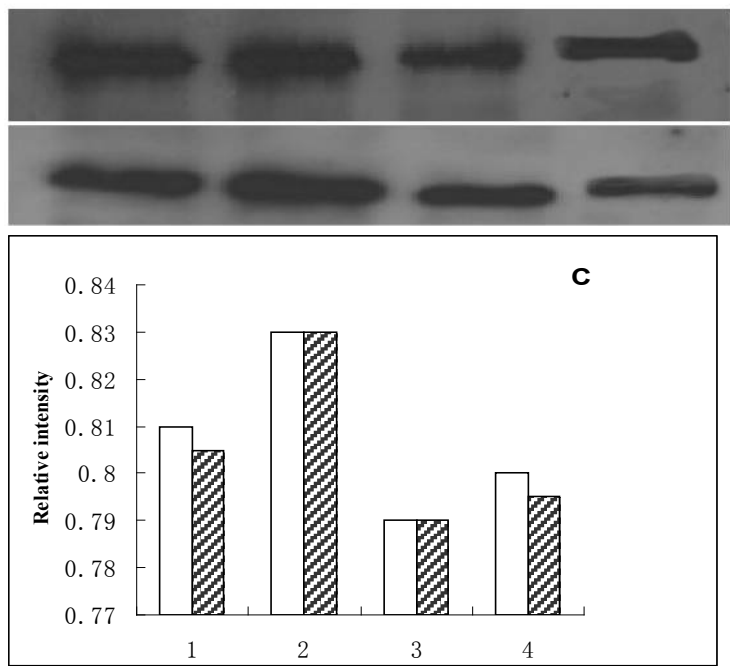

Fig. 3 (A) The amounts of yields at different times. Control group: RTS reaction without GNPs; Test group: RTS reaction with $1.2 \mathrm{~nm}$ GNPs.

(B) Bioactivity analysis of RTS yields by Western Blotting. Blank: No. 1 to No.4: 40 ng, 50 ng, 20 ng, 30 ng of RTS yields with $0.24 \mathrm{~nm}, 0.48 \mathrm{~nm}, 2.4 \mathrm{~nm}, 3.6 \mathrm{~nm}$ GNPs, respectively; Black diagonal: No.1 to No.4: $40 \mathrm{ng}$ $50 \mathrm{ng}, 20 \mathrm{ng}, 30 \mathrm{ng}$ RTS yields without GNPs, respectively.

(C) Relative scanning intensity of hybridization signals in Fig. 3B.

To further investigate the function of gold nanoparticles with a diameter of $5 \mathrm{~nm}$ in the course of peptide synthesis, we used the Western blot analysis to compare the bioactivity of peptide yields from RTS reagents with and without $1.2 \mathrm{nM}$ gold nanoparticles. As shown in Fig.
$3 \mathrm{~B}$ and $\mathrm{C}$, the intensity of yield from RTS reagents with gold nanoparticles is stronger than that from RTS reagents without gold nanoparticles, however, there is no statistical difference between the bioactivities of the peptide yields from the two RTS reagents $(p>0.05)$. These results show that gold nanoparticles with a diameter of $5 \mathrm{~nm}$ do not decrease the bioactivity of synthesized peptides, and that they even may improve the bioactivity of yields.

\section{Potential mechanism}

In short, the gold nanoparticles with a diameter of $5 \mathrm{~nm}$ can improve the efficiency of in vitro gene transcription-translation system. In order to investigate the mechanism underlying this improvement, we hypothesized that the gold nanoparticles may improve the bioactivity of T7 RNA polymerase, aminoacyl-tRNA synthetase and ribosome. In order to confirm this point, we compared with enzymatic bioactivity of aminoacyltRNA synthetase with or without GNPs. As shown in Fig. 4, GNPs can improve the efficiency of tRNA-14C Arginine composite synthesis, which suggest that GNPs can act as a bio-catalyst [19, 22-24] to improve the bioactivity of those enzymes such as aminoacyl-tRNA synthetase and ribosome enzyme, which finally results in the enhancement of in vitro gene transcription-translation efficiency.

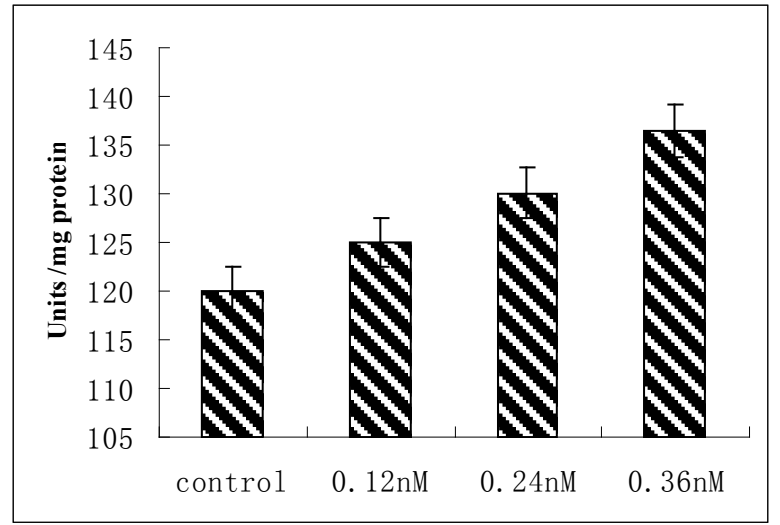

Fig. 4 Units /mg protein (aminoacyl-tRNA synthetase) with different concentration of GNPs

In addition, properties of GNPs may help to improve the efficiency of in vitro gene transcription-translation. First, since gold nanoparticles have a high surface/volume ratio, their addition to RTS reagents can significantly change the distribution of reaction components. All the necessary components for transcription and translation such as amino acids, DNA fragments, T7 RNA polymerases, ribosomes, and transcription factors, etc. can be attracted toward gold nanoparticles as the result of Van der Waals and electrostatic interactions [16, 24, 29, 30]. Therefore, the gold nanoparticles in the RTS solution may become small reaction centers. Second, at the beginning of gene transcription-translation in the course of RTS, as the temperature increases rapidly, the thermal entropy in the reagent and the surface energy of the gold nanoparticles also increase [33-35]. The result is 
that all the components speed up the Brownian motion, which raises the probability of dynamic contact among gene fragment A2 and T7RNA polymerases, amino acids and tRNA, and mRNA and ribosomes around the gold nanoparticles. This contact, in turn, enhances the probability of right base-pairing and transcription between T7 RNA polymerase and gene fragment A2, and also between ribosome and mRNA fragments. During the course of peptide synthesis, the gold nanoparticles may act as single-strand binding proteins, similar to their role in the course of PCR [26, 28], which improves the chance that amino acids rightly bind with ribosome and mRNA templates, which, in turn decreases or even eliminates the probability of wrong base-pairing between amino acids and tRNAs and between ribosome and mRNA fragments, and enhance the synergistic action of all biomolecules in RTS reaction.

Regarding the effects of gold nanoparticles on the bioactivity of synthesized peptides, some reports show that gold nanoparticles can be used as supports for enzymes [17, 18], can enhance the stability of adsorbed enzyme molecules relative to micro- or macro-scale supports, and, finally, can preserve or enhance enzyme bioactivity in the nanocomposites; therefore, gold nanoparticles may act as a molecular "chaperone" $[5,6]$ in the course of RTS, stabilizing the structure of peptides, which means that gold nanoparticles do not decrease the bioactivity of synthesized peptides.

Together, all of the factors mentioned above have the possibility to improve the efficiency of RTS. However, this kind of dose-product effect requires an optimum concentration of gold nanoparticles; after passing a critical concentration point of $1.2 \mathrm{~nm}$, gold nanoparticles decrease or inhibit in-vitro gene transcription-translation. The concrete mechanism underlying this inhibition still needs further clarification. Future work will focus on investigating the interaction between GNPs and these key enzymes such as T7 RNA polymerase, aminoacyl-tRNA synthetase and ribosome, and the potential mechanism of GNPs improving the synergetic function of a lot of biomolecules in the course of RTS.

Numerous reports have been mentioned above, but so far there have been no reported studies closely associated with the effects of nanoparticles on the course of gene transcription and translation. Our study, which is the first of its kind, shows that gold nanoparticles can markedly affect the course of gene transcription and translation like siRNA and microRNA.

\section{Conclusion}

In conclusion, our results directly demonstrate that gold nanoparticles of $5 \mathrm{~nm}$ in diameter can markedly improve the efficiency of a gene transcription-translation system, and that the smaller size and surface properties of the gold nanoparticles may be responsible for this improvement. Our results also indirectly suggest that gold nanoparticles may improve the bio-activity of T7 RNA polymerases,
aminoacyl-tRNA synthetase and ribosome involved in the course of gene transcription-translation and, therefore, even may act as a biocatalyst. Based on our research, it is evident that gold nanoparticles have great potential for invitro applications such as large-scale protein fabrication, gene transcription-translation regulation, and studies of structure and function of toxic protein. It should be noted, however, that our results also indirectly demonstrate that gold nanoparticles of $5 \mathrm{~nm}$ in diameter that enter into human cells could interfere with gene transcription and protein synthesis, resulting in toxic effects on the human cells, which means that in-vivo applications could be limited.

\section{Acknowledgements}

This work was supported by the budget of the "Strategic Fund for Establishing the International HQs of Universities in Waseda University", and China 863 Project (No.2007AA022004), China 973 project (2010CB933901), New Century Excellent Talent of Ministry of Education of China(NCET-08-0350), Special Infection Diseases Key Project of China (2009ZX10004311), Shanghai Science and Technology Fund (10XD140 6100). The authors are grateful to Visiting Professor Robert DiGiovanni of Waseda University for critical review of the manuscript.

\section{References}

1. Ullis KB, Faloona FA Specific synthesis of DNA in vitro via a polymerase-catalyzed chain reaction. Methods Enzymol. 1987; 155:335-350.doi:10.1016/0076-6879(87)55023-6

2. Zubay G. In vitro synthesis of protein in microbial systems. Annu. Rev. Genet. 1973; 7:267-287.doi:10.1146/annurev.ge.07.120173. 001411

3. Drexler KE. Nanosystems- molecular machinery, manufacturing, and computation. John Wiley \& Sons, Inc., New York, 1999; 1-8.

4. Lee BS, Lee SC, Holliday LS. Biochemistry of mechanoenzymes: biological motors for nanotechnology. Biomed Microdevices. 2003; 5:269-280.doi:10.1023/A:1027324811709

5. Kerner MJ, Naylor DJ, Ishihama Y, Maier T. et al Proteome-wide analysis of chaperonin-dependent protein folding in Escherichia coli. Cell. 2005; 122:209-220.doi:10.1016/j.cell.2005.05.028

6. Schlieker C, Bukau B, and Mogk A. Prevention and reversion of protein aggregation by molecular chaperones in the E. coli cytosol: implications for their applicability in biotechnology. J. Biotechnol. 2002; 96:13-21.doi:10.1016/S0168-1656(02)00033-0

7. Spirin AS, Baranov VI, Ryabova LA, Ovodov SY, Alakhov YB. A continuous cell-free translation system capable of producing polypeptides in high yield. Science. 2001; 242:1162-1164.doi:10.1126/ science. 3055301

8. Hino M, Shinohara Y, Kajimoto K, Terada H, BabaYRequirement of continuous transcription for the synthesis of sufficient amounts of protein by a cell-free rapid translation system. Protein Expression Purif. 2002; 24: 255-259.doi:10.1006/prep.2001.1570

9. Martin GA, Kawaguchi R, DeGiovanni A, Fukushima M, Mutter W, High-yield, in vitro protein expression using a continuous-exchange, coupled transcription/translation system. Biotechniques. 2001; 31: $948-950$.

10. Han Y, Deng J, Huan Y, Gao F, Pan B, Cui D. Expression of singlechain Fv gene specific for $\gamma$-seminoprotein by RTs and its biological activity identification. Biotechnology Progress. 2006; 22:1084-1089. doi:10.1021/bp0504445

11. Iskakova MB, Szaflarski W, Dreyfus M, Remme J, Nierhaus KH. Troubleshooting coupled in vitro transcription-translation system derived from Escherichia coli cells: synthesis of high-yield fully 
active proteins. Nucleic Acids. Res. 2006; 34:e135.doi:10.1093/nar/ gk1462

12. Kim DM, Swartz JR. Prolonging cell-free protein synthesis by selective reagent additions. Biotechnol. Prog. 2000; 16:385-390. doi: $10.1021 / \mathrm{bp} 000031 \mathrm{y}$

13. Makarova OV, Makarov EM, Sousa R, Dreyfus M. Transcribing of Escherichia coli genes with mutant T7 RNA polymerases: stability of lacZ mRNA inversely correlates with polymerase speed. Proc. Natl. Acad. Sci. USA. 92; 12250-12254.doi:10.1073pnas.92.26 12250

14. Bonner G, Lafter E- M, Sousa R Characterization of a set of T7 RNA polymerase active site mutants. J. Biol. Chem. 1994; 269 : 25120-25128.

15. Chamberlin M,Ring J. Characterization of T7-specific ribonucleic acid polymerase I. General properties of the enzymatic reaction and the template specificity of the enzyme. J. Biol. Chem. 1973;248:223 $5-2244$

16. Pan B, Cui D, Sheng Y, Ozkan CS, Gao F, et al Dendrimer-modified magnetic nanoparticles enhance efficiency of gene delivery system. Cancer Res. 2007; 67:8156-8163.doi:10.1158/0008-5472.CAN-064762

17. Rosi NL, Giljohann DA, Thaxton CS. Lytton Jean AKR, Han MS Mirkin CA. Oligonucleotide-modified gold nanoparticles for intracellular gene regulation. Science. 2006; 312:1027-1030.doi:10. $1126 /$ science. 1125559

18. Pan B, Ao L, Gao F, Tian H, He R, Cui D End-to-end self-assembly and colorimetric characterization of gold nanorods and nanospheres via oligonucleotide hybridization. Nanotechnology. 2005; 16:17761780.doi:10.1088/0957-4484/16/9/061

19. Wang P. Nanoscale biocatalyst systems. Current Opinion in Biotechnology. 2006; 17: 574-579.doi:10.1016/j.copbio.2006.10.009

20. Chen H, Gao F, He R, Cui D. Chemiluminescence of luminol catalyzed by silver nanoparticles. Journal of Colloid and Interface Science. 2007; 315;158-163.doi:10.1016/j.jcis.2007.06.052

21. Cui D. Advance and prospect of biomolecules functionalized carbon nanotubes. J. Nanosci Nanotechnol. 2007; 7:1298-314.doi:10.1166/ jnn.2007.654

22. Gole A, Dash C, Soman C, Sainkar SR, Rao M, Sastry M. On the preparation, characterization, and enzymatic activity of fungal protease-gold colloid bioconjugates. Bioconjugate Chem.2001; 12:684-690.doi:10.1021/bc0001241

23. Caruso F, Schuler C. Enzyme multilayers on colloid particles: assembly, stability, and enzymatic activity. Langmuir. 2000; 16: 9595-9603.doi:10.1021/la000942h
24. Asuri P, Karajanagi SS, Yang HC, Yim TJ, Kane RS, Dordick JS. Increasing protein stability through control of the nanoscale environment. Langmuir. 2006; 22:5833-5836.doi:10.1021/la0528450

25. Cui D, Tian FR, Kong Y, Igor T, Gao H. Effects of Single wall carbon nnaotubes on polymerase chain reaction. Nanotechnology 2004; 15:154-157.doi:10.1088/0957-4484/15/1/030

26. Li H, Huang J, Lv J, An H, Zhang X, Zhang Z, Fan C, Hu J. Nanoparticle PCR: Nanogold-assisted PCR with enhanced specificity. Angew. Chem. Int. Ed. 2005; 44:5100-5103.doi:10.1002an ie.2005 00403

27. Li M, Lin YC, Wu CC, Liu HS. Enhancing the efficiency of a PCR using gold nanoparticles. Nucleic Acids Research. 2005; 33:184. doi:10.1093/nar/gni183

28. Lewicki BT, Margus T, Remme J, Nierhaus KH. Coupling of rRNA transcription and ribosomal assembly in vivo-formation of active ribosomal subunits in Escherichia coli requires transcription of rRNA genes by host RNA polymerase which can not be replaced by bacteriophage-T7 RNA polymerase. J. Mol. Biol.1993; 231:581593.doi:10.1006/jmbi.1993.1311

29. McIntosh CM, Esposito EA, Boal AK, Simard JM, Martin CT, Totello VR Inhibition of DNA transcription using cationic mixed monolayer protected gold clusters. J. Am. Chem. Soc. 2001;123: 7626-7629.doi:10.1021/ja015556g

30. Stamm M, Sommer JU.. Entropy and enthalpy at play. Nature mater. 2007; 6:260-261.doi:10.1038/nmat1880

31. Korgel BA. Interfaces behaving well. Nature Mater. 2007; 6:551-552. doi:10.1038/nmat1969

32. Brummelkamp TR, Bernards R, Agami R. A system for stable expression of short interfering RNAs in mammalian cells. Science 2002; 296:550-553.doi:10.1126/science.1068999

33. Bartel DP. MicroRNAs: Genomics, biogenesis, mechanism, an function. Cell. 2004; 116:281-297.doi:10.1016/S0092-8674(04) 00045-5

34. Cui D, Jin G, Gao TW, Sun T, Tian F, Estrada GG, Gao H, Sarai A Characterization of BRCAA1 and its novel epitope identification. Cancer Epidemiol Biomarkers Prev. 2004; 13:1136-1145.

35.Nishimura S, Harada F, Narushima U, Seno T. Biochimica Et Biophysica Acta. 1967; 142:133-148.

Copyright:(c) 2011 DX. C, et al. This is an openaccess article distributed under the terms of the Creative Commons Attribution License, which permits unrestricted use, distribution, and reproduction in any medium, provided the original author and source are credited. 